\title{
THE SOLUBILITY OF TRIBUTYL PHOSPHATE IN AQUEOUS SOLUTIONS
}

BY

\author{
L. L. BURGER AND R. C. FORSMAN
}

TECHNICAL DIVISIONS

APRIL 2, 1951

\section{CAUTION}

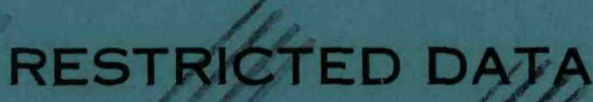

THIS DOCUMENT CONTAINS RESTRICTED DATA AS DEFINED IN THE ATOMIC ENERGY ACT OF 1946 WHICH AEFECTS THE NATIONAL DEFENSE OF THE UNITED STATES. ITS TRANSMITTAL OR THE DISCLOSURE OF ITS CONTENTS IN ANY MANNER TO AN UNAUTHORIZED PERSON IS PROHIBITED AND MAY RESULT IN SEVERE PENALTIES UNDER APPLICABLE FEDEBAL LAWS.

\section{HANFORD WORKS} RICHLAND, WASHINGTON

\section{GENERAL ELECTRIC}

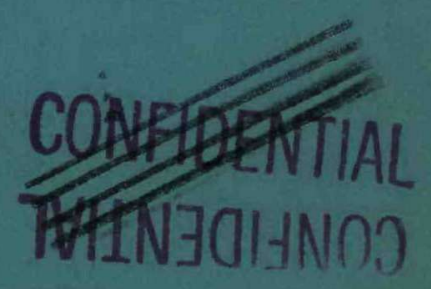

UNCLASSIFIED

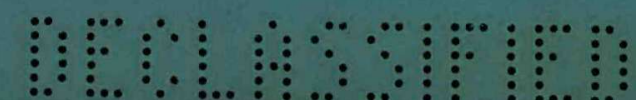




\section{DISCLAIMER}

This report was prepared as an account of work sponsored by an agency of the United States Government. Neither the United States Government nor any agency Thereof, nor any of their employees, makes any warranty, express or implied, or assumes any legal liability or responsibility for the accuracy, completeness, or usefulness of any information, apparatus, product, or process disclosed, or represents that its use would not infringe privately owned rights. Reference herein to any specific commercial product, process, or service by trade name, trademark, manufacturer, or otherwise does not necessarily constitute or imply its endorsement, recommendation, or favoring by the United States Government or any agency thereof. The views and opinions of authors expressed herein do not necessarily state or reflect those of the United States Government or any agency thereof. 


\section{DISCLAIMER}

Portions of this document may be illegible in electronic image products. Images are produced from the best available original document. 
Photostat Price $\$$ 3.30

Microfilm Price

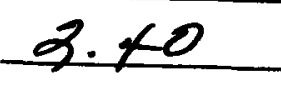

Available from the

Office of Technical Services

Department of Commerce

Washington 25, D. C.
UNCLASSIFED !

HW-20936

Chemistry - Separation

Processes for Plutonium

And Uranium

\section{THE SOLUBILITY OF TRIBUTYL PHOSPHATE}

IN AQUEOUS SOLUTIONS

By

L. L. Burger and R. C. Forsman

Chemical Research Section

Separations Technology Division

April 2, 1951

- T:

HANFORD WORKS

RICHLAND, WASHINGTON

Operated for the Atomic Energy Commission

by the

General Electric Company

under

Contract \# W-31-109-Eng-52

\section{LEGAL NOTICE}

This report was prepared as an account of Government sponsored work. Neither the United Statos, nor the Commission, nor any person acting on behalf of the Commission:

A. Makes any warranty or representation, express or implied, with respect to the accuracy, completeness, or usefulness of the information contained in this report, or that the use of any information, apparatus, method, or process disclosed in this report may not infringe privately owned rights; or

B. Assumes any liabilities with respect to the use of, or for damages resulting from the use of any information, apparatus, method, or process disclosed in this report.

As used in the above, "person acting on behalf of the Commission" includes any employee or contractor of the Commission to the extent that such employee or contractor prepares, handles or distributes, or provides access to, any information pursuant to his employment or contract with the Commission.

$i 6 j \quad: 3$

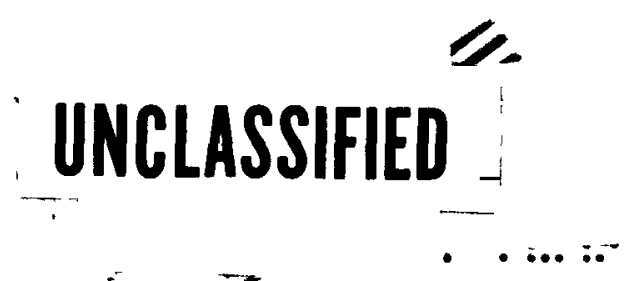


HW-20936

\section{THE SOLUBILITY OF TRIBUTYL PHOSPHATE IN AQUEOUS SOLUTIONS}

L. L. Burger and R. C. Forsman

\section{INTRODUCTION}

The solvent tributyl phosphate (TBP) has a lower solubility in water than most uranium solvents that have been employed. However, because it is potentially hydrolyzable to non-volatile species, which have adverse effects on process operation, the amount that is carried with the various aqueous streams in an extraction process has greater importance. The solubility relations are also of theoretical interest in that they represent a balance between the highly polar oxygen which favors miscibility with water and the alkyl groups which are hydrophobic in nature.

Solubilities of pure TBP and of TBP in an inert diluent were determined in water and in solutions of nitric acid of various concentrations. Measurements were also made in solutions typical of various process streams, such as the Metal Recovery RAW and RCU streams, and in more concentrated uranyl nitrate solutions. In the case of the TBP-diluent-water system the equilibrium water content in the organic phase was also determined.

\section{SUMMARY AND CONCLUSIONS}

1. The solubility of pure TBP in water is about $0.4 \mathrm{~g} / 1$ at $25^{\circ} \mathrm{C}$. When the TBP is diluted with an inert substance insoluble in water, the solubility of TBP decreases but is much higher than predicted by the mol fraction.

2. The presence of salts in the aqueous phase decreases the solubility markedly. In $2 \mathrm{M} \mathrm{UO}_{2}\left(\mathrm{NO}_{3}\right)_{2}$ solution or in $\mathrm{RAW}$ the solubility is only $1 / 20$ of that in pure water. The solubility in dilute nitric acid solutions is affected similarly. However, because of competing effects such as the formation of $\mathrm{TBP}-\mathrm{HNO}_{3}$ complexes the solubility of TBP decreases slowly with increasing nitric acid concentration, passes through a minimum and then becomes quite

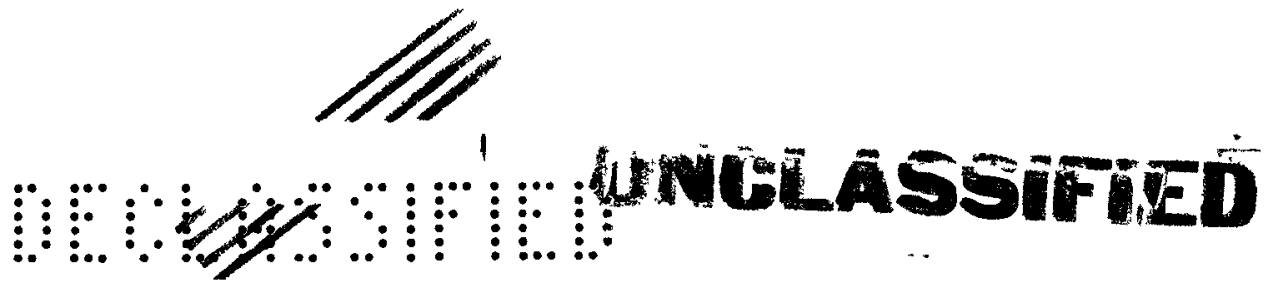


soluble in concentrated nitric acid solutions.

3. Concentration of aqueous solutions by evaporation appears to reduce the TBP content without appreciable hydrolysis. A considerable excess of TBP can be removed by steam-distillation during such a process.

4. The aforementioned low solubility of TBP in salt solutions together with its ready stripping by evaporation should lead to a very low residual phosphate contamination of product uranium on concentration of the RCU stream preparatory to oxide conversion.

5. The solubility of water in TBP-diluent mixtures varies from $64 \mathrm{~g} / 1$ in pure TBP to about $0.06 \mathrm{~g} / 1$ in a pure paraffin-type diluent. The solubility of water is only 2 and $8 \mathrm{~g} / 1$ in $121 / 2 \%$ and $30 \% \mathrm{TBP}$, respectively.

6. Several analytical procedures for use with small quantities of TBP such as found in aqueous solutions have been compared.

\section{EXPERIMENTAL}

The availability of TBP containing $P^{32}$, a convenient beta emitter, permitted more accurate analytical determinations than were previously possible. A sample of TBP containing tracer phosphorus was obtained from $W_{\circ} H_{\circ}$ Baldwin of ORNL. At the time this work was started the activity was about $0.1 \mathrm{mc} / \mathrm{ml}$. Before using, the TBP was washed with a sodium carbonate solution to remove any butyl acid and phosphate impurities and then washed several times with water.

The organic phase in this work consisted of pure TBP or of TBP diluted with AMSCO-125-90 W, a paraffinic hydrocarbon diluent of average molecular weight of about 160 . Dilutions to $16 \%$ and $33 \%$ were employed and in the case of the determinations in pure water dilutions of $8 \%, 50 \%$ and $75 \%$ were also employed. The solutions were also given the sodium carbonate-water pretreatment described above.

Solubility determinations were carried out by adding $200 \lambda$ of the organic solution to about $21 / 2 \mathrm{ml}$ of the aqueous phase. This was stirred or shaken for 2-3 hours at $25^{\circ} \mathrm{C}$. sentrifuged and the excess of organic phase removed

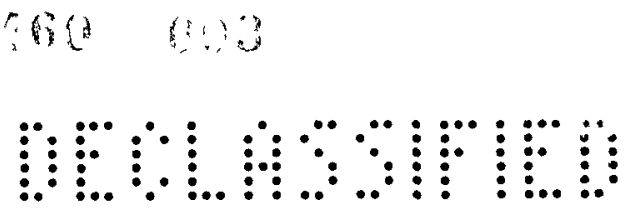


from the surface. A measured sample of the aqueous phase, the size depending on the solubility and the specific activity of the TBP, was then removed and placed in a $3 \mathrm{ml}$ centrifuge cone. The dissolved TBP was extracted with four $200 \lambda$ fractions of $n$-hexane and the hexane transferred directly to a $25 \mathrm{~mm}$ watch glass where it was evaporated to dryness (10-30 minutes) at room temperature. Experiments with repeated hexane extractions indicated that four $200 \lambda$ fractions were adequate to remove all the TBP from the aqueous phase. The watch glass was mounted on an aluminum tray, covered with a layer of cellophane and counted. Standardization of the method was provided by making up known concentrations of TBP in $\mathbf{n}$-hexane and evaporating aliquots on the watch glasses. Frequent standardization was employed because of the relatively short, 14.3 days, half-life of the $P^{32}$. Tests showed no loss of TBP by volatilization when the watch glasses were exposed to the air for times up to several hours at room temperature. However, attempts to carry out the hexane evaporation under a heat lamp produced appreciable losses.

The solubility in nitric acid solution was obtained with vacuum distilled, "cold" TBP. The equilibrations were carried out in the same manner and the aqueous phase analyzed by infrared absorption as described in the appendix.

Water in the organic phase was determined with Karl-Fischer reagent.

\section{RESULTS AND DISCUSSION}

The solubility of TBP in water is reported in the industrial literature as about $0.6 \%$ or $6 \mathrm{~g} / 1$. This is considerably higher than preliminary values obtained by the Chemical Reasearch Section which were of the order of 0.1 to $0.6 \mathrm{~g} / 1$ (1). The solubility found in the present work, $0.39 \mathrm{~g} / 1$, falls in the latter range.

Table I lists the solubility data for TBP in pure water. The mol fractions are based on an assumed molecular weight of 160 for the hydrocarbon diluent, while the activity coefficient is based on pure TBP as the standard state. It will be seen that the solubility increases rapidly as the concentration of TBP in the diluent increases, e.g., at a mol fraction of $0.2 \mathrm{TBP}$, the solubility is $70 \%$ of that of pure TBP. The data are shown graphically in Figure 1.
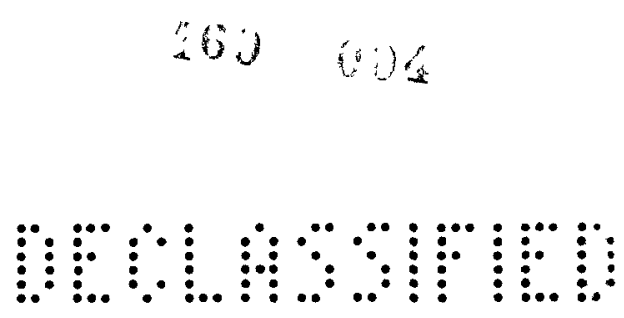


\section{Table I}

SOLUBILITY OF TBP IN WATER AT $25^{\circ} \mathrm{C}$.

\section{Mol}

\begin{tabular}{|c|c|c|c|c|}
\hline $\begin{array}{c}\text { Conc. TBP } \\
\text { in Diluent } \\
\text { Vol. } \% \\
\end{array}$ & $\begin{array}{c}\text { Fraction } \\
\text { TBP in } \\
\text { Diluent } \\
\end{array}$ & $\begin{array}{l}\text { Solubility } \\
\mathrm{g} / 1 \\
\end{array}$ & $\begin{array}{c}\text { Relative } \\
\text { Solubility } \\
\end{array}$ & $\begin{array}{l}\text { Activity Coefficient } \\
\text { TBP in Diluent* }\end{array}$ \\
\hline 100 & 1.00 & 0.39 & 1.00 & 1.00 \\
\hline 75 & 0.700 & 0.33 & 0.86 & 1.2 \\
\hline 50 & 0.436 & 0.29 & 0.74 & 1.7 \\
\hline 33.3 & 0.280 & 0.28 & 0.72 & 2.6 \\
\hline 16.6 & 0.134 & 0.24 & 0.62 & 4.6 \\
\hline 8.3 & 0.066 & 0.17 & 0.44 & 6.6 \\
\hline
\end{tabular}

*See text

In contrast to these small numbers, the solubility of water in pure TBP is quite large, $64 \mathrm{~g} / 1$. This corresponds to a mol fraction of 0.51 , suggesting a 1:1 complex. The solubility of water in TBP-diluent mixtures is given in Table II and Figure 2. It will be seen that the water content falls well below the 1:1 mol ratio at the higher TBP dilutions. It has been previously noted that addition of uranyl nitrate to TBP solutions causes the water content to drop. With this organic phase, water is apparently not included in the coordination sphere of the uranyl nitrate (2), and the water content of such a solution seems to follow the curve in Figure 2 , i. e., follows the concentration of free TBP. For example, Rehn and Slansky ${ }^{(3)}$ found a water solubility of $0.5 \mathrm{~g} / 1$ in a $15 \%$ TBP solution made $0.2 \mathrm{M}$ in uranyl nitrate. The free TBP in such an organic phase would be $0.15 \underline{\mathrm{M}}$ or $4.6 \%$ by volume. From Figure 2 , a $4.6 \%$ TBP solution would have a water content of about $0.4 \mathrm{~g} / 1$, in good agreement with the observed value.

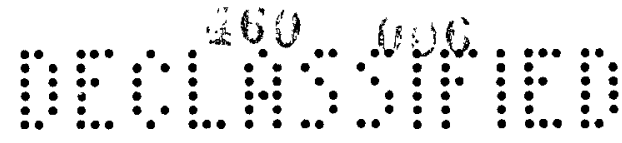




\section{9}

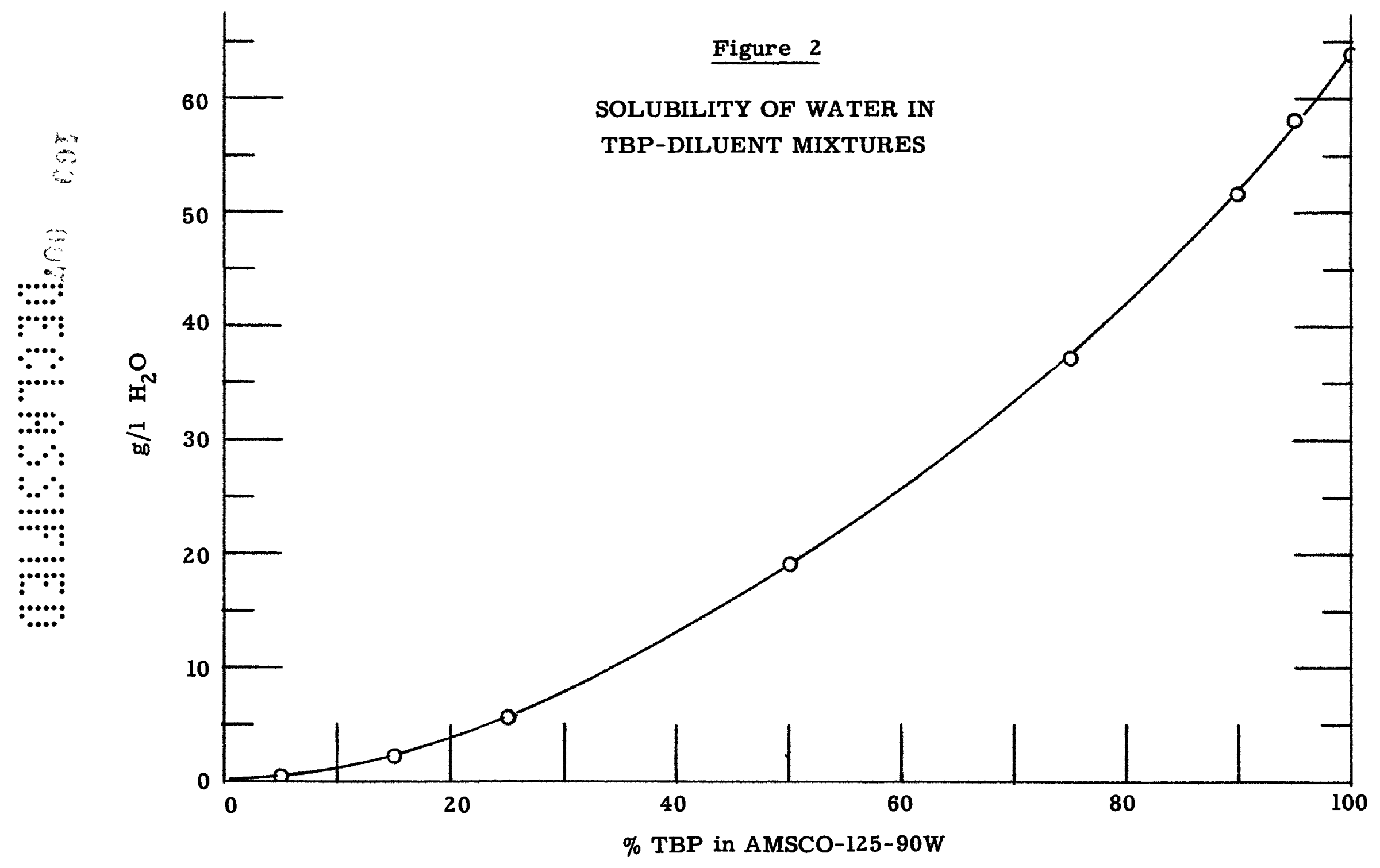


Table II

SOLUBILITY OF WATER IN

TBP-AMSCO-125-90 W MIXTURES AT $25^{\circ} \mathrm{C}$.

Dry Composition

\begin{tabular}{r} 
Vol. \% \\
In Dilu \\
\hline 100 \\
95 \\
90 \\
75 \\
50 \\
25 \\
15 \\
5 \\
0
\end{tabular}

Index of

Refraction

1.42256

95

90

75

50

25

15

5

0

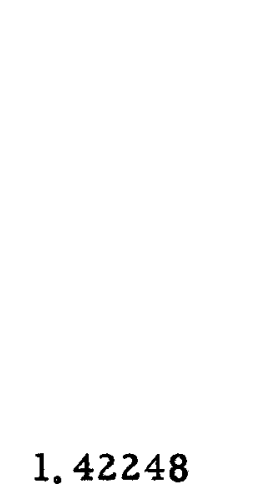

\begin{tabular}{ccc}
\multicolumn{3}{c}{ Water-Saturated Composition } \\
\hline $\begin{array}{c}\mathrm{H}_{2} \mathrm{O} \\
\mathrm{g} / 1\end{array}$ & $\begin{array}{c}\text { Index of } \\
\text { Refraction }\end{array}$ & $\begin{array}{c}\text { Mol Ratio } \\
\text { TBP/ } \mathrm{H}_{2} \mathrm{O}\end{array}$ \\
63.7 & 1.41727 & 0.97 \\
58.0 & 1.41748 & 1.01 \\
51.5 & 1.41785 & 1.09 \\
37.1 & 1.41851 & 1.28 \\
19.2 & 1.41975 & 1.67 \\
5.8 & 1.42106 & 2.79 \\
2.4 & 1.42158 & 4.09 \\
0.54 & 1.42207 & 6.00 \\
0.06 & 1.42235 & --
\end{tabular}

As indicated in Table II the index of refraction of the dry solvent varies but slightly with TBP concentration thus, the index of refraction of the wet solvent is an analytical measure of its water content.

Solubilities of TBP corresponding to typical extraction process conditions are listed in Table III. Solubility falls off rapidly as the concentration of electrolyte rises, e.g., the amount of TBP dissolved in the RAW solution is only $1 / 20$ of that dissolved in pure water. This is lower than one would predict from the decrease in water activity alone. It is interesting to note that Jamrack and co-workers ${ }^{(4)}$ found the solubility of diethylene glycol dibutyl ether ("Butex") in water decreased by a factor of 30 when ammonium nitrate was added to form a solution of slightly greater ionic strength than the RAW solution in question. 
Table III

SOLUBILITY OF TBP (g/l) IN PROCESS SOLUTIONS AT $25^{\circ} \mathrm{C}$.

$16.6 \%$ and $33 \%$ TBP in AMSCO $125-90 \mathrm{~W}$

Organic

Phase

Aqueous Phase

\begin{tabular}{|c|c|c|c|c|c|}
\hline$\%$ ТВP & $\mathrm{H}_{2} \mathrm{O}$ & $0.06 \underline{\mathrm{M}} \mathrm{HNO}_{3}$ & $0.3 \underline{\mathrm{M}} \mathrm{HNO}_{3}$ & $2 \underline{\mathrm{M}} \mathrm{UO}_{2}\left(\mathrm{NO}_{3}\right)_{2}$ & RAW* \\
\hline 33.3 & 0.28 & 0.19 & 0.21 & - & 0.0097 \\
\hline 16.6 & 0.24 & 0.17 & 0.17 & 0.01 & 0.0097 \\
\hline
\end{tabular}

* RAW consisted of $2.6 \underline{\mathrm{M}} \mathrm{HNO}_{3}, 1.9 \underline{\mathrm{M}} \mathrm{NaNO}_{3}, 0.2 \underline{\mathrm{M}} \mathrm{Na}_{2} \mathrm{SO}_{4}, 0.2 \underline{\mathrm{M}} \mathrm{Na}_{2} \mathrm{PO}_{4}$, $0.03 \underline{\mathrm{M}} \mathrm{NH}_{4} \mathrm{NO}_{3}, 0.02 \underline{\mathrm{M}} \mathrm{FeCl}_{3}, 0.03 \underline{\mathrm{M}} \mathrm{NH}_{2} \mathrm{SO}_{2} \mathrm{OH}$.

In the concentration of aqueous process streams, the fate of small amounts of TBP is of considerable importance and several experiments were carried out in which the TBP-saturated aqueous solutions were concentrated by evaporation. It was found that for solutions containing electrolytes, e.g. , uranyl nitrate, the TBP content dropped in accordance with its normal solubility, i. e. f followed the decreased water activity and no build-up of TBP or its decomposition products occurred. When a slight excess of TBP was added prior to the evaporation, the excess distilled out rapidly. That this would be expected is evident from the following considerations: The ratio of the vapor pressure (5) (6) (7) of TBP to water is about $1.2 \times 10^{-3}$ at $100-130^{\circ} \mathrm{C}$. Multiplying by the molecular weight ratio $266 / 18$ gives $3.5 \times 10^{-2}$ as the weight ratio of TBP to $\mathrm{H}_{2} \mathrm{O}$ expected on stream distillation.

Examination of the residue from these evaporations were carried out, after hexane extraction, by adding carrier $\mathrm{PO}_{\overline{4}} \overline{\text { and }}$ precipitating ammonium phosphomolybdate using a modified molybdate citrate reagent. Negligible activity was found indicating no appreciable hydrolysis of the TBP. When uranium was present, interference of its daughter products during counting was prevented by carrying out a preliminary lanthanum fluoride precipitation. Boric acid was then added to complex the fluoride ion and the ammonium phosphomolybdate

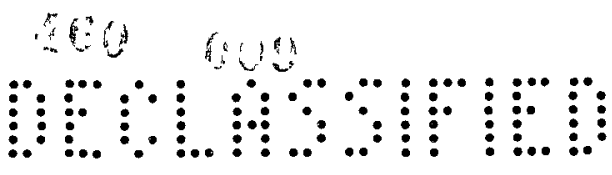


precipitation carried out as above. Residues were also examined for organic phosphate by this procedure after refluxing a $1 \mathrm{ml}$ sample with $15 \mathrm{ml}$ of fuming nitric acid. The maximum amount found corresponded to a total phosphate of less than $0.004 \mathrm{~g} / 1$ of $\mathrm{PO} \overline{\overline{4}}$.

The decreased solubility of TBP in salt solutions together with the apparently easy stripping by evaporation imparts a favorable aspect to the concentration of the RCU and other process solutions.

The solubility of pure TBP in nitric acid solutions was found to decrease linearly with nitric acid concentration to about $6 \underline{M}$, reach a minimum of $0.14 \mathrm{~g} / 1$ at about $8 \underline{\mathrm{M}}$, and then increase rapidly to about $1.2 \mathrm{~g} / 1$ at $15 \underline{\mathrm{M}}$ The data are given in Table IV and Figure 3. Apparently, in the higher acid concentrations the strong attraction of the acid molecules more than balances the decreased water activity. It is probable that TBP is very soluble in pure $\mathrm{HNO}_{3}$.

The solubility of non-ionizing substances in water is governed primarily by their ability to form hydrogen bonds. However, to ascertain the effect of other factors such as the type of alkyl groups in the molecule, the solubility should be referred to a fixed fugacity. Table $\mathrm{V}$ lists some representative solubilities corrected to a vapor pressure of the solute at $1 \mathrm{~mm} \mathrm{Hg}$. On this basis the solubility of TBP in water is seen to be reasonably large.

Table IV

SOLUBILITY OF PURE TBP IN NITRIC ACID SOLUTIONS AT $25^{\circ} \mathrm{C}$.

\begin{tabular}{|c|c|c|c|}
\hline Conc. $_{\underline{M}} \mathrm{HNO}_{3}$ & $\begin{array}{l}\text { TBP Solubility } \\
\mathrm{g} / 1\end{array}$ & $\underset{\underline{M}}{\text { Conc. } \mathrm{HNO}_{3}}$ & $\begin{array}{l}\text { TBP Solubility } \\
\text { g/1 }\end{array}$ \\
\hline 0.00 & 0.39 & 9.61 & 0.17 \\
\hline 0.79 & 0.36 & 12.0 & 0.29 \\
\hline 1.97 & 0.31 & 13.8 & 0.61 \\
\hline 4.01 & 0.24 & 15.6 & 1.56 \\
\hline 6.41 & 0.16 & & \\
\hline
\end{tabular}




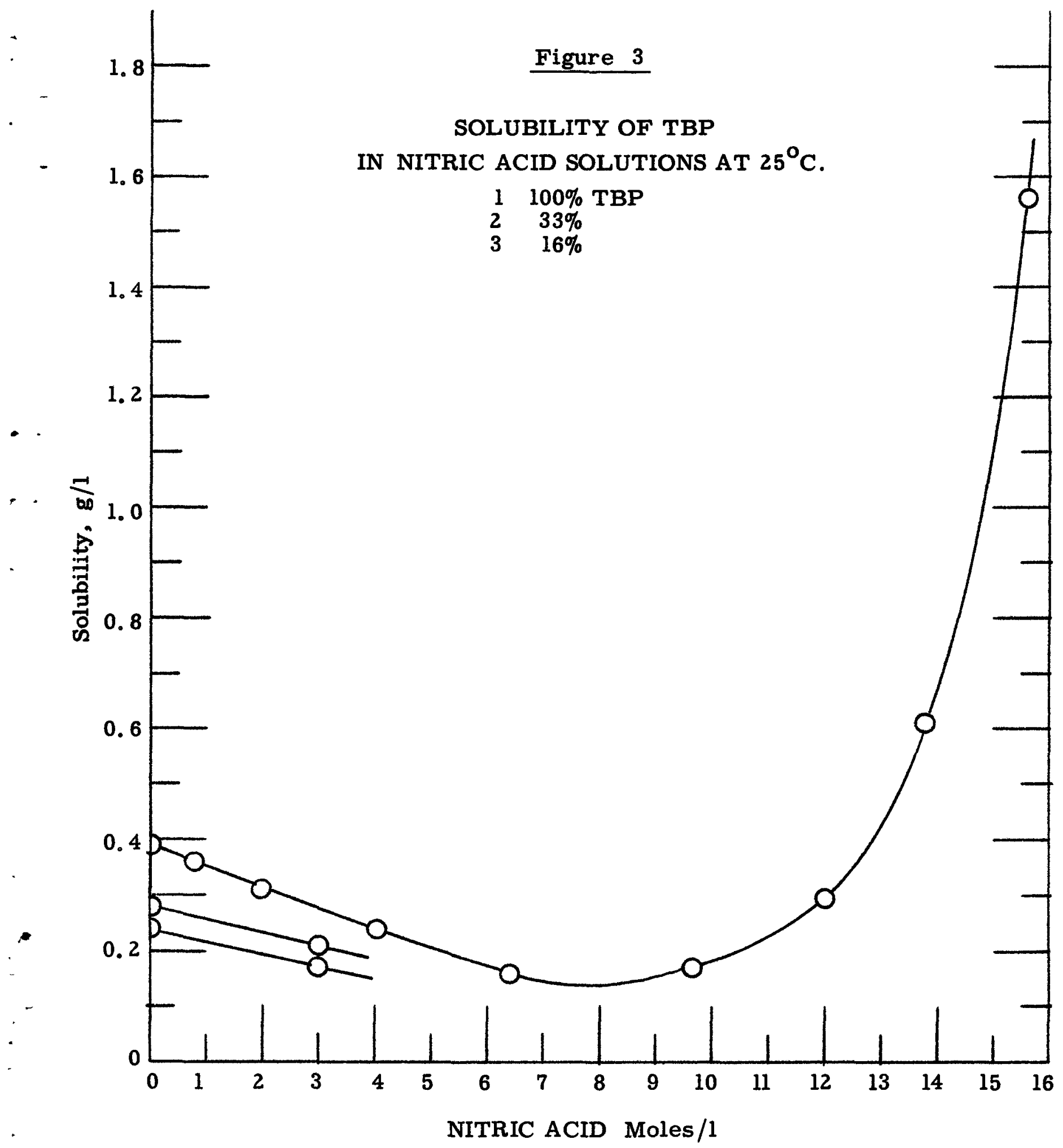


Table V

RELATIVE SOLUBILITIES OF ORGANIC COMPOUNDS IN WATER AT $25^{\circ} \mathrm{C}$.

\begin{tabular}{|c|c|c|c|}
\hline \multirow[b]{2}{*}{ Substance } & \multirow{2}{*}{$\begin{array}{l}\text { Vapor Press, at } \\
25^{\circ} \mathrm{C} ., \mathrm{mm} \mathrm{Hg}\end{array}$} & \multicolumn{2}{|c|}{ Solubility mols $/ 1000 \mathrm{~g} \mathrm{H} 2 \mathrm{O}$} \\
\hline & & At Vapor Pressure, & At $1 \mathrm{~mm} \mathrm{Hg}$, Calc. \\
\hline TBP & $0.006(9)$ & $1.5 \times 10^{-3}$ & $0.2(2)$ \\
\hline n-Butyl alcohol & 6.0 & 1.15 & 0.19 \\
\hline Hexone & 19 & 0.17 & 0.0090 \\
\hline $\begin{array}{l}\text { Diethylisobutyl } \\
\text { Phosphate }\end{array}$ & $0.06(2)$ & 0.068 & 1.1 \\
\hline $\begin{array}{l}\text { Dibutyl ethyl } \\
\text { phosphate }\end{array}$ & $0.03(6)$ & 0.017 & $0.4(7)$ \\
\hline
\end{tabular}

The change in solubility with temperature was not investigated in this study but from previous work it is known to be small. This is substantiated by the observation that diethylisobutyl phosphate shows a minimum solubility in the vicinity of $75^{\circ} \mathrm{C}$, only $15 \%$ lower than the solubility at $25^{\circ} \mathrm{C}$. (8). Cloudpoint tests with TBP indicate that a similar minimum solubility may exist in the range $30-90^{\circ} \mathrm{C}$.

APPENDIX - ANALYTICAL PROCEDURES

The analytical method for small amounts of TBP, i.e., < $1 \mathrm{mg}$, previously employed in connection with the Metal Recovery program consists of decomposing the ester by refluxing with fuming nitric acid for 3 hours, followed by the molybdenum blue ${ }^{(9)}(10)$ colorimetric procedure for phosphate. As it was desirable to employ a chemical decomposition to check the residues from evaporation experiments and to check for complete extraction of TBP by the hexane using the evaporation technique, this method of decomposition was examined as to its applicability.

One to ten milligram samples of TBP containing known amounts of the tracer TBP and phosphate ion added as carrier were refluxed for 3 hours with fuming nitric acid, using $25 \mathrm{ml}$ flasks fitted with reflux condensers. Formic acid was then added dropwise to decompose the nitric acid. The phosphate was

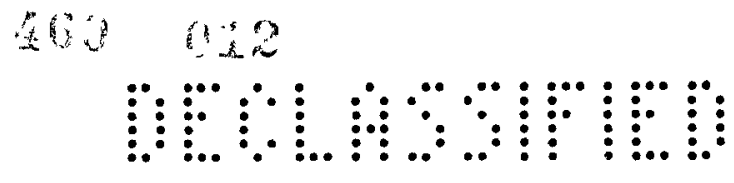


then precipitated as ammonium phosphomolybdate and the precipitate collected on a small filter pad and counted. The total phosphate was then obtained by dissolving the precipitate in $0.1 \mathrm{~N} \mathrm{NaOH}$ and back-titrating with $0.1 \mathrm{~N} \mathrm{HCl}$, using the procedure of Kassner ${ }^{(11)}$.

These experiments indicated a recovery of 93-100\% of the carrier phosphate, but only 80-90\% of the TBP. Greatly increasing the reflux time gave the same result, suggesting that incomplete TBP decomposition was probably not the cause. In another experiment a dry-ice trap was connected to the reflux condenser and the condensate from the reaction, mostly $\mathrm{NO}_{2}$, examined for $\mathbf{P}^{32}$. No activity was found indicating negligible loss by volatilization.

The 10-20\% loss of TBP is as yet unexplained. In view of the uncertainty of this method and the time required, it was decided to attempt another decomposition method. A variety of procedures for organic phosphates has been described in the literature ${ }^{(12)}$ and a number of these have been tested by the Methods Control Group under D. F. Shepard. Recently an alternate procedure which looked promising was developed by C. W. Pollock in that laboratory. This method involves heating the sample of TBP in a few $\mathrm{ml}$ of carbon tetrachloride with $500 \lambda$ concentrated sulfuric acid at $175-200^{\circ} \mathrm{C}$. for 3 minutes after the carbon tetrachloride has evaporated. This is followed by a short digestion at the boiling point with $5 \mathrm{ml}$ concentrated nitric acid and a few drops of $4 \%$ ammonium persulfate to decompose the residual organic matter. (13) When used by the authors, this procedure led to recoveries of $98-100 \%$, in agreement with Pollock ${ }^{\natural}$ s work.

For sample sizes of 5-10 mg TBP this decomposition was followed by phosphomolybdate precipitation and titration as described above. For quantities less than $1 \mathrm{mg}$, e.g., of the order found in $1-10 \mathrm{ml}$ of aqueous solutions, a colorimetric procedure was seen to be desirable. A series of tests carried out by the analytical service group under E. W. Christopherson indicated that the nitric acid and persulfate treatments were not necessary and the decomposition was followed directly by the colorimetric procedure, which consisted of dilution with $1 \mathrm{M} \mathrm{H}_{2} \mathrm{SO}_{4}$ and addition of the ammonium molybdate and stannous chloride reagents. At the present time an uncertainty of about $\pm 30 \%$ is indicated and it

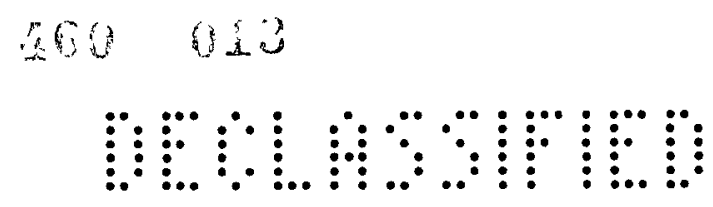


must be admitted that the method is not completely satisfactory. Refinements of the colorimetric step involving extraction of the molybdate complex before reduction have been reported to increase the accuracy to better than $\pm 2 \%$ 。

Concurrent with this analytical work R. H. Moore of the Physical Methods Group was studying the determination of tributyl phosphate in or ganic dilutents by infrared absorption. Moore was successful in adapting this method to aqueous solutions by extracting $25-100 \mathrm{ml}$ of the aqueous solution with carbon tetrachloride and concentrating by evaporation to $0.3-4.0 \mathrm{~g} / 1 \mathrm{TBP}$. The absorption was measured at $1031 \mathrm{~cm}^{-1}$ and $1061 \mathrm{~cm}^{-1}$ and the results indicated a precision of about $\pm 0.02 \mathrm{~g} / 1 \mathrm{TBP} .{ }^{(15)}$ In the determinations of the solubility of pure TBP in the nitric acid solutions, the aqueous solutions were analyzed by this method.

\section{ACKNOWLEDGMENT}

We are indebted to W. H. Baldwin of the Oak Ridge National Laboratories for furnishing the sample of radioactive TBP.

In addition to the work of $\mathrm{C}$. W. Pollock previously described, the authors gratefully acknowledge the work of Marjorie $\mathrm{K}$. Temple on the colorimetric method and of $\mathrm{R}$. $\mathrm{H}$. Moore on the several determinations made by the infrared method.

REFERENCES

(1) Slansky, C. M. Progress Report for January, 1950, Chemical Research Section. HW-16076, p. 16 .

(2) Burger, L. L., and C. M. Slansky. Density and Viscosity of Solutions in the Tributyl Phosphate Process for Uranium Recovery. HW-15233, p. 5 (1949).

(3) Rehn, I. M., and C. M. Slansky. Batch Countercurrent Equilibria of Uranium and Nitric Acid in the Tributyl Phosphate Process for Waste Uranium Recovery. HW-19696, p. 12 ff (1950).

(4) Jamrack, W. D., et al. Plutonium Separation, Part 12 - Physical Data for the Primary Separation Plant. AERE-X/2-360 (1949).

(5) Noller, C. R., and G. R. Dutton. J. Am. Chem. Soc. 55, 424 (1933).

(6) Vogel, A. I., and D. M. Cowen. J. Chem. Soc. 1943, 16-24.

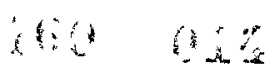


(7) Wagner, R. M. , and C. M. Slansky. Evaporation of Process Streams in the Tributyl Phosphate Process. HW-15172, p. 8 (1949).

(8) Burger, L. L. Unpublished data.

(9) Truog, E., and A. H. Meyer. Ind. Eng. Chem., Anal. Ed., 1, 136 (1929).

(10) Berenblum, I., and E. Chain. Biochem. J. 32, 286 (1938).

(11) Kassner, J. L., H. P Crammer and M. A. Ozier. Anal. Chem. 20, 1052 (1948).

(12) Simmons, W. R., and J. H. Robertson. Ibid, 22, 294 (1950).

(13) Pollock, G. W. Unpublished work.

(14) Kirk, P. L., et al. HEW Analytical Development Program. CN-1791, p. $18(1944)$.

(15) Moore, R. H. To be published.

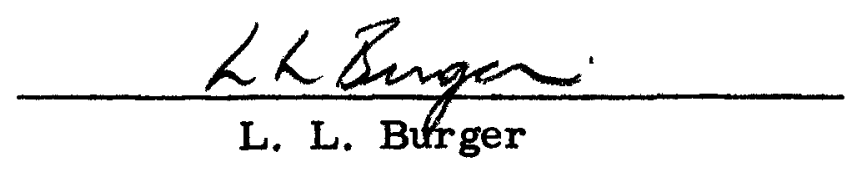

LLB, RCF:dt

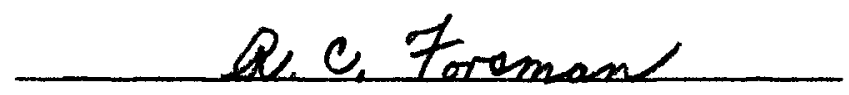

R. C. Forsman

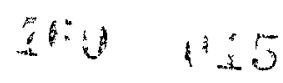

